\title{
Congenital Facial Nerve Palsy
}

National Cancer Institute

\section{Source}

National Cancer Institute. Congenital Facial Nerve Palsy. NCI Thesaurus. Code C101198.

Partial or complete paralysis of the facial muscles of one side of an individual's face that is present at birth. It is caused by damage to the seventh cranial nerve. 